\title{
Da planta ao fitocosmético: uma experiência teórico-prática com alunos de escolas públicas
}

\author{
Plant to phytocosmetics: a theoretical practical experience with students of public \\ schools
}

RESUMO

A oficina "Da planta ao fitocosmético" integra o projeto de extensão da Faculdade de Farmácia (FF) da Universidade Federal do Rio de Janeiro (UFRJ) intitulado "Estabelecimento de uma relação multidisciplinar construtiva com as escolas públicas: uma contribuição da Faculdade de Farmácia da UFRJ". Essa oficina foi trabalhada com alunos de uma escola de ensino fundamental e uma escola de ensino médio, ambas localizadas no município do Rio de Janeiro. O seu objetivo principal foi promover o contato dos alunos e dos professores de escolas públicas com a universidade, gerando e difundindo o conhecimento técnico-científico e humanístico sobre a importância dos hábitos de higiene para a saúde e informaçóes sobre plantas utilizadas como fitocosmético. Para tal, foram ofertadas oficinas teóricas e práticas nas escolas, de modo a promover a interação dialógica entre os alunos e os professores de escolas públicas com a Universidade. Neste contexto, foi possível aproximá-los de atividades, materiais e conceitos sobre autocuidado, bem estar, hábitos de higiene, cosméticos e fitocosméticos. Os professores que acompanharam os alunos nas escolas sentiram-se encorajados a manter a criatividade em sala de aula. Para os acadêmicos, o projeto possibilitou o crescimento pessoal e técnico, e foram instigados a desenvolver aptidóes além da sala de aula.

Palavras-chave: Fitocosméticos. Extensão universitária. Escola pública.

\section{ABSTRACT}

The "Plant to phytocosmetics" workshop is part of the extension project of the Pharmacy Faculty, Federal University of Rio de Janeiro (UFRJ), entitled "Establishment of a constructive multidisciplinary relationship with public schools: a contribution of the Pharmacy Faculty of UFRJ". This workshop was developed with students from a primary and secondary school, both located in the city of Rio de Janeiro. Its main objective was to promote the contact of students
Mariana Sato de Souza de Bustamante Monteiro

Doutora em Ciências de Polímeros pelo Instituto de Macromoléculas Professora Eloisa Mano, Universidade Federal do Rio de Janeiro, Brasil; professora adjunta da Faculdade de Farmácia da Universidade Federal do Rio de Janeiro, Brasil. (marianasato@pharma.ufrj.br).

Antônio Ferreira Mombrini da Silva

Graduando em Farmácia na Universidade Federal do Rio de Janeiro, Brasil; monitor e estagiário no projeto de extensão "Farmácia Universitária" (FF/UFRJ) (antoniomombrini1@gmail. com).

Theo Luiz Ferraz de Souza

Doutor em Química Biológica pela Universidade Federal do Rio de Janeiro, Brasil; professor adjunto da Faculdade de Farmácia da Universidade Federal do Rio de Janeiro, Brasil; coordenador do projeto de extensão "Estabelecimento de uma relaçáo multidisciplinar construtiva com as escolas públicas: uma contribuição da Faculdade de Farmácia da UFRJ". (theo@pharma.ufri.br)

Adriana Passos Oliveira

Doutora em Química pela Universidade Federal do Rio de Janeiro, Brasil, com período sanduíche no Departament of Pharmaceutical Sciences, Universidade de Basel, Suíça; professora adjunta da Faculdade de Farmácia da Universidade Federal do Rio de Janeiro, Brasil. (adrianapassos@pharma.ufrj.br). 
and teachers of public schools with the University by generating and disseminating technical-scientific and humanistic knowledge about the importance of hygiene habits for health and information about plants used as phytocosmetics. For that, theoretical and practical workshops were offered in the schools, in order to promote the dialogical interaction between the students and the teachers of public schools with the University. In this context, it was possible to approach them with activities, materials and concepts on self-care, well-being, hygiene habits, cosmetics and phytocosmetics. The teachers who accompanied the students in the school felt encouraged to maintain creativity in the classroom. For the academics, the project enabled personal and technical growth, and they were instigated to develop skills beyond the classroom.

Keywords: Phytocosmetics. University extension. Public school.

\section{INTRODUÇÃO}

A extensão universitária é concebida como um processo interdisciplinar educativo, cultural, científico e político que promove a interação transformadora entre universidade e outros setores da sociedade, mediante o envolvimento de alunos, docentes e técnicos administrativos, do corpo social da Universidade, em açóes voltadas para atender as demandas da população. As suas diretrizes compreendem: interação dialógica; interprofissionalidade e interdisciplinaridade; indissociabilidade entre ensino, pesquisa e extensão; impacto na formação do estudante e impacto social (FORPROEX, 2012).

O princípio da interação dialógica orienta que o desenvolvimento das relaçóes entre Universidade e setores sociais deve ser marcado pelo diálogo e troca de saberes, ampliando o acesso e a democratização do saber (BENETTI; SOUSA; SOUZA, 2015). Nessa complexa sociedade, a extensão universitária configura-se como uma das formas de atuação mais necessárias, pois a Universidade é uma instituição educacional que expressa a realidade social e política da sociedade a qual faz parte. Dessa forma, o impacto da extensão universitária na transformação social, voltada para os interesses e necessidades da maioria da população, é propiciador do desenvolvimento social e regional e de aprimoramento das políticas públicas (FORPROEX, 2012).
Os condenados são chamados de recuperandos para evitar o uso de rótulos como preso, interno, apenado, condenado e encarcerado, que acabam por depreciar o aspecto humano e retiram a subjetividade e a essência do sujeito em questão. 
As atividades de extensão universitária têm sua relevância por serem um "laboratório" de aprendizagem profissional e oxigenação do conhecimento produzido na Universidade. Por meio de suas açôes, possibilita a geração de novos conhecimentos de forma interdisciplinar e contribui para a formação cidadá e profissional dos estudantes universitários, criando oportunidade de trabalho a partir da realidade concreta e cooperação para a construção de uma sociedade cada vez mais justa, ética, fraterna, igualitária e democrática (SANTOS , 2014).

É indiscutível a importância das atividades práticas e experimentais no ensino fundamental e ensino médio. Todavia, as inserçôes dessas práticas são pouco difundidas, em razão de alguns fatores, como a falta de infraestrutura nas escolas e a dificuldade dos profissionais em elaborar protocolos que consigam abordar uma nova dinâmica de ensino. Mais importante do que a inserção da prática experimental é a articulação dela à base teórica e à sua essência na natureza e na vida cotidiana dos alunos ou como base científica para a futura vida acadêmica dos estudantes (DA SILVA et al., 2016).

Outro ponto que permeia a vivência escolar é a promoção de vida saudável. Com base nos princípios da Carta de Ottawa ${ }^{1}$, para promover a saúde não é suficiente apenas informar, mas também é necessário estabelecer uma relação dialógica, na qual os sujeitos sejam envolvidos na ação educativa, formativa, construtiva e criativa, levando em consideraçáo a reconstrução do saber e do fazer (CORRÊA et al., 2015).

Uma das estratégias de incentivo à promoção de vida saudável e melhoria na qualidade de vida, principalmente para crianças e adolescentes, é a prática de autocuidado, higiene pessoal e bemestar. É perceptível que nas últimas décadas cada vez mais pessoas busquem na estética resultados que elevem a sua autoestima, bemestar e automotivação. A automotivação é um termo que vem sendo citado para designar os impulsos ou motivos que levam o ser humano a agir com entusiasmo, felicidade e prazer. Ressalta-se que, na ausência de uma autoestima positiva, o crescimento psicológico do indivíduo pode ficar comprometido (BRANDEN, 2009, p. 10). Atualmente, o mercado oferece inúmeros cosméticos e produtos de higiene com o intuito de melhorar a qualidade de vida, saúde, beleza e contribuir nesse processo de automotivação e melhora da autoestima
A Carta de Ottawa é um documento que foi apresentado na Primeira Conferência Internacional sobre Promoção da Saúde, realizado em Ottawa, capital do Canadá, em novembro de 1986. É uma Carta de Intenções que busca contribuir com as políticas de saúde em todos os países, de forma equânime e universal. 
(OLIVEIRA et al., 2016).

A preocupação com o autocuidado e bem-estar aliada ao uso de ativos da biodiversidade brasileira - uma vez que o Brasil possui uma enorme biodiversidade, em torno de 15 a $20 \%$ do total mundial e uma rica diversidade étnica e cultural - têm motivado a pesquisa e o desenvolvimento de produtos de higiene e cosméticos utilizando esses materiais. O Fitocosmético pode ser definido como o cosmético que contém o ativo natural, de origem vegetal, seja um extrato, óleo ou óleo essencial, cuja ação biológica define a atividade do produto (FIGUEIREDO, 2014). A utilização de plantas medicinais na promoção da saúde é uma prática de origem antiga realizada na atualidade por diversas comunidades (SANTOS et al., 2016).

O grupo da oficina "Da planta ao fitocosmético” está vinculado ao projeto de extensão "Estabelecimento de uma relação multidisciplinar construtiva com as escolas públicas: uma contribuição da Faculdade de Farmácia da UFRJ". O objetivo principal da oficina foi promover o contato dos alunos e dos professores de escolas públicas com a universidade, por meio de oficinas sobre hábitos de higiene, uso de plantas medicinais e elaboração de fitocosméticos.

\section{METODOLOGIA}

O projeto em referência é uma ação de extensão realizada no município do Rio de Janeiro, cadastrado na plataforma de Sistema de Informação de Projetos (SIGProj) pelo EDITAL RUA-UFRJ 2016 (Protocolo no 232087.1188.129019.08042016) com apoio da Fundação de Amparo à Pesquisa do Estado do Rio de Janeiro (FAPERJ), Edital E36/2014 - Apoio à melhoria do ensino nas escolas da rede pública sediadas no RJ (número de processo FAPERJ E-26/010.002790/2014), sob a coordenação do professor Theo Luiz Ferraz de Souza.

O projeto não precisou da aprovação do comitê de ética, uma vez que seu objetivo consistiu em gerar conhecimento que poderá ser utilizado pela sociedade a qual se destina.

O projeto iniciou-se em julho de 2015 com a participaçáo de 47 docentes e três técnicos da Faculdade de Farmácia (FF/UFRJ), divididos em 12 grupos distintos, separados por afinidades de áreas 
de conhecimento, para desenvolver atividades no "Dia da Ciência com a Faculdade de Farmácia - UFRJ" em duas escolas públicas do município do Rio de Janeiro.

As 12 oficinas do projeto abordaram as seguintes temáticas: Anemia; Vacinação; Proteínas; Preservação da qualidade da água; Proteção solar; Alimentos funcionais; Drogas; A luz na ciência e tecnologia; Tipos sanguíneos; Parasitas humanos; Vírus, Bactérias e Fungos; Medicamentos; Medicamentos Homeopáticos; Fitocosméticos; Plantas medicinais; Plantas alimentícias; Descarte de medicamentos; Poluentes e Agrotóxicos.

Uma das temáticas envolveu a oficina "Da planta ao fitocosmético", com a participação de dez alunos de graduação da FF/UFRJ e dois alunos de pós-graduação, recrutados por meio de e-mail, cartazes e divulgação em sala de aula. Como critérios de seleção foram considerados: serem acadêmicos da instituição, estarem cursando a partir do 8o período e terem disponibilidade de participar do projeto como voluntários, por pelo menos um semestre.

As duas escolas da rede pública participantes eram do município do Rio de Janeiro: a Escola Municipal Tenente Antônio João, localizada na Ilha do Fundão; o Colégio Estadual Professora Maria de Lourdes de Oliveira Lavor, localizado na Ilha do Governador. As atividades ocorridas na Escola Municipal contaram com a participação de 127 alunos, incluindo alunos do primeiro ( $1^{\circ}$ ao $5^{\circ}$ ano) e do segundo segmento ( $6^{\circ}$ ao $9^{\circ}$ ano), e 10 professores do ensino fundamental. No Colégio Estadual participaram 1.600 alunos do ensino médio ( $1^{\circ}$ ao $3^{\circ}$ ano) e 10 professores, durante os anos de 2016 e 2017.

A oficina "Da planta ao fitocosmético" apresentou todo o processo de autocuidado, hábitos de higiene, plantas medicinais utilizadas para a promoção da saúde e produção de fitocosméticos. Foi utilizada a metodologia ativa, na qual os estudantes de graduação da FF foram inseridos tanto no processo de ensino quanto de aprendizado e passaram a ser membros ativos na construção do saber por meio de estímulos sobre o conhecimento e a análise dos problemas apresentados.

A oficina envolveu diferentes etapas em sua implantação, a saber: planejamento, construção e implantação. Na primeira etapa, buscou- 
se levantar e compreender as demandas relacionadas ao hábito de higiene, processo de autocuidado e bem-estar dos alunos das escolas participantes. Essa etapa ocorreu em julho de 2015, com duas reunióes de duas horas, sendo uma reunião no colégio estadual e outra, na escola municipal, onde se realizou uma conversa com dois professores de cada escola, para conhecermos os diferentes níveis de escolaridade dos alunos, o tipo de informação adequada para cada faixa etária, o que deveria ser disponibilizado acerca dos cuidados com a saúde, condiçôes de vida, percepção de qualidade de vida, necessidades e carências no processo de autocuidado e bem-estar.

A segunda etapa consistiu na construção pelos discentes do material abordado na oficina. Inicialmente, foi realizada uma reuniáo em agosto de 2015, de quatro horas, com os alunos, para conversarmos sobre a temática e as atividades que deveriam ser elaboradas. Em seguida, os acadêmicos realizaram uma revisão bibliográfica na internet, livros de medicina e farmácia, assim como nas principais bases de dados, como Scielo, PubMed, Science direct, para a elaboração de folhetos informativos, pôsteres e as atividades práticas da oficina. As atividades foram desenvolvidas observando-se a faixa etária dos estudantes e as necessidades apontadas pelos professores das escolas. Para o desenvolvimento das oficinas práticas foi utilizada uma metodologia que permitiu que as temáticas fossem trabalhadas de forma dinâmica e de fácil compreensão, de modo a atrair a atenção dos alunos, como por exemplo: manuseio das plantas medicinais; desenvolvimento de formulações cosméticas, utilizando plantas medicinais; e aplicação das formulaçóes desenvolvidas pelos participantes. Essa etapa de elaboraçáo durou cerca de dois meses, com encontros de duas horas, duas vezes por semana.

A etapa de implantação consistiu na aplicação da oficina nas escolas. $\mathrm{Na}$ escola municipal, os 127 alunos foram divididos em grupos de 20 pessoas, as oficinas teóricas e práticas ocorreram durante duas manhãs, em abril de 2016, e as atividades duraram em média uma hora. Na escola estadual, os 1600 alunos foram divididos em grupos de 15 pessoas e as atividades ocorreram durante seis dias, nos três turnos manhã, tarde e noite, com duração média de 40 minutos. Para atender à demanda, as atividades foram divididas em três etapas: dois dias em setembro de 2016, dois dias em novembro de 2016 e dois dias em novembro de 2017. Durante as atividades foram distribuídos os 
folhetos informativos desenvolvidos aos participantes e os acadêmicos de farmácia realizaram explicaçóes sobre as seguintes temáticas: acne, caspa, olheiras, hidratação da pele e mau hálito, utilizando pôster, livros, plantas medicinais e os fitocosméticos desenvolvidos. Os participantes das escolas públicas manusearam plantas medicinais (como por exemplo, espinheira santa, orégano, calêndula e sálvia) e desenvolveram alguns fitocosméticos e produtos de higiene a partir desses produtos naturais, como por exemplo, a infusão com orégano e sálvia para o tratamento da caspa e utilização como antisséptico bucal. Os alunos também foram orientados acerca do método de obtenção de produtos de higiene e cosméticos a base de plantas e produtos naturais, com qualidade satisfatória, para aumentar a acessibilidade a essas preparaçóes, que podem influenciar de forma positiva no processo de saúde e autocuidado, além de valorizar a biodiversidade brasileira e a cultura popular. Os recursos para a aquisição dos materiais foram provenientes do auxílio recebido pela Fundação de Amparo à Pesquisa do Estado do Rio de Janeiro (FAPERJ).

\section{RESULTADOS E DISCUSSÃO}

Atualmente a extensão universitária constitui uma ação dentro das universidades brasileiras que viabiliza a inserção dos acadêmicos em contato direto com a sociedade, dando-lhes oportunidade de vivenciar a aplicaçáo dos conhecimentos da sua futura profissão, a complementaridade de outros conhecimentos e a viabilidade do aprendizado interdisciplinar e prático fora da sala de aula.

A oficina "Da planta ao fitocosmético" contou com a participação de dez alunos de graduação e dois alunos de pós-graduação da FF/ UFRJ que se envolveram em todas as etapas do projeto, desde o planejamento e construção até a implantação e execução da oficina. Destaca-se a participação dos discentes nas etapas de construção dos materiais e nas atividades de implantação da oficina.

A experiência interdisciplinar desenvolvida durante essa ação, por intermédio de discussão-ação-reflexão-transformação, contribuiu ativamente para estimular o espírito crítico e a refletir sobre cidadania e o papel social da educação superior, confirmando a indissociabilidade da relação ensino-pesquisa-extensão. Nessa perspectiva, os estudantes 
foram protagonistas da sua formação técnica, visto que participaram de forma ativa na obtenção das competências necessárias à atuação no projeto; contribuíram com ideias no processo de construção do saber, unindo a teoria com a prática; desenvolveram atividades em equipe; e, ainda, aprenderam a investigar as fontes de informação antes de disseminar um conteúdo. Os acadêmicos também foram protagonistas da sua formação cidadá, pois se reconheceram como agentes de transformaçáo social, quando em contato com as questóes e demandas da sociedade e entenderam a necessidade de respeitar opinióes diferentes.

No âmbito da relação entre extensão e pesquisa, reafirmou-se a indissociabilidade pela participação de estudantes de pós-graduação na oficina "Da planta ao fitocosmético", contribuindo para a qualificação dessa ação extensionista.

O segundo envolvimento foi a produçáo acadêmica gerada a partir dessa atividade de extensão, como a apresentação de dois pôsteres na Semana de Integração Acadêmica, da UFRJ, um em 2016 e outro em 2017, e a apresentação de um pôster no VI Simpósio Interno de Ensino, Pesquisa e Extensão, da Faculdade de Farmácia, da UFRJ, em 2017, o qual ganhou prêmio de primeiro lugar na categoria de alunos de graduação.

Outro ponto importante foi à formação dos futuros farmacêuticos, com perfil adequado às necessidades e políticas de saúde do país, pois as práticas vivenciadas durante a oficina potencializaram as relaçóes centrais dos acadêmicos na formação em saúde. O incentivo para a atuação interdisciplinar dos futuros farmacêuticos implica na formação de futuros profissionais que respeitaráo os princípios do Sistema Único de Saúde (SUS) e atuarão com responsabilidade junto à populaçáo.

Os docentes responsáveis pela oficina "Da planta do fitocosmético" tornaram-se mediadores do processo de conhecimento, pois trabalharam em conjunto com os discentes compartilhando conceitos e estimulando o pensamento crítico, representando um apoio para o aluno. Dessa forma, o professor não representa mais o ator principal em sala de aula e, o eixo pedagógico clássico "estudante-professor" foi substituído pelo eixo "estudante-professor-comunidade". 
A participação tanto dos discentes quanto dos docentes na oficina da "Planta ao Fitocosmético" favoreceu o contato direto com a realidade social do município do Rio de Janeiro e, desta forma, proporcionou a ampliação de novas competências e habilidades e estímulos à aplicação clara e objetiva dos conhecimentos teóricos adquiridos e da atitude investigadora. Outra contribuição positiva foi a sociabilização dos conhecimentos científicos, a possibilidade da vivência interdisciplinar e o aprofundamento de conhecimentos teóricos e práticos.

A própria sociedade deve expor os problemas a serem solucionados, e em consonância a essa realidade, os professores das escolas municipais e estaduais participantes especificaram o tipo de informaçáo sobre hábitos de higiene, autocuidado e bem-estar que os alunos necessitavam, e os pontos destacados foram: higiene da pele, acne, caspa, problemas bucais. Tendo conhecimento desse contexto, a oficina abordou as seguintes temáticas: anatomia e fisiologia da pele, tipos de pele, principais cuidados, produtos de higiene, preparaçóes cosméticas, plantas medicinais, ou seja, a parte das plantas que possuem algum fim medicinal, de fácil acesso e comum na realidade dos alunos, como: orégano, sálvia, espinheira santa, calêndula, entre outras e fitocosméticos. Os produtos de higiene e fitocosméticos propostos foram: antisséptico bucal com sálvia, sabonete de espinheira santa, infusão de orégano e infusão de calêndula.

A oficina criou atividades para incentivar a participação dos alunos de nível fundamental e médio na investigação científica, no desenvolvimento de uma capacidade crítica, consciente e integrada. Isso ocorreu por meio do desenvolvimento de habilidades como a manipulação de plantas medicinais e fitocosméticos, bem como o desenvolvimento destes. Um ambiente solidário também foi criado com estimulo da vida saudável, qualidade de vida, promoção da saúde, e com objetivo de produzir repercussóes positivas sobre os determinantes da saúde dos membros da comunidade escolar. Nos quadros 1 e 2 estão apresentadas as atividades desenvolvidas com plantas medicinais para a obtenção de fitocosméticos. 
Quadro 1 - Plantas medicinais utilizadas na oficina "Da planta ao fitocosmético" para o desenvolvimento de fitocosméticos

\begin{tabular}{|c|c|c|c|c|}
\hline Nome & Principais Usos & Formulação & Modo de Usar & Fonte \\
\hline $\begin{array}{l}\text { Maytenus } \\
\text { ilicifolia } \\
\text { (Espinheira } \\
\text { Santa) }\end{array}$ & $\begin{array}{l}\text { Acne, afecção } \\
\text { da pele, alergia, } \\
\text { eczema, escara, } \\
\text { ferida, herpes e } \\
\text { psoríase }\end{array}$ & $\begin{array}{l}\text { Sabonete de } \\
\text { Glicerina }\end{array}$ & Lavar o corpo & $\begin{array}{l}\text { ROSSATO } \\
\text { et al. (2012) }\end{array}$ \\
\hline $\begin{array}{l}\text { Origanum } \\
\text { vulgare } \\
\text { (Orégano) } \\
\end{array}$ & Anticaspa & Infusão & $\begin{array}{l}\text { Uso externo: } \\
\text { enxaguar o } \\
\text { cabelo }\end{array}$ & $\begin{array}{l}\text { RUPPELT } \\
\text { et al. (2015) }\end{array}$ \\
\hline $\begin{array}{l}\text { Calendula } \\
\text { (Calêndula) }\end{array}$ & $\begin{array}{l}\text { Anti- } \\
\text { inflamatória e } \\
\text { cicatrizante }\end{array}$ & Infusão & $\begin{array}{l}\text { Uso externo: } \\
\text { aplicar sobre o } \\
\text { local afetado, } \\
\text { com auxílio de } \\
\text { algodáo } \\
\end{array}$ & $\begin{array}{l}\text { BRASIL } \\
(2011)\end{array}$ \\
\hline $\begin{array}{l}\text { Salvia } \\
\text { officinalis } \\
\text { (Sálvia) }\end{array}$ & $\begin{array}{l}\text { Antisséptico } \\
\text { bucal contra } \\
\text { mau hálito, } \\
\text { aftas, afecçóes } \\
\text { na gengiva, } \\
\text { garganta e boca }\end{array}$ & Infusão & $\begin{array}{l}\text { Fazer } \\
\text { bochechos }\end{array}$ & $\begin{array}{l}\text { RUPPELT } \\
\text { et al. (2015) }\end{array}$ \\
\hline $\begin{array}{l}\text { Matricaria } \\
\text { chamomilla } \\
\text { (Camomila) }\end{array}$ & $\begin{array}{l}\text { Olheiras e } \\
\text { inchaços }\end{array}$ & Infusão & $\begin{array}{l}\text { Uso externo: } \\
\text { aplicar, } \\
\text { gelado, sobre } \\
\text { as pálpebras, } \\
\text { com auxílio de } \\
\text { algodáo }\end{array}$ & $\begin{array}{l}\text { NEIVA; } \\
\text { NEIVA; } \\
\text { RIBEIRO } \\
(2013)\end{array}$ \\
\hline $\begin{array}{l}\text { Camellia } \\
\text { sinensis } \\
\text { (Chá verde) }\end{array}$ & $\begin{array}{l}\text { Olheiras e } \\
\text { inchaços }\end{array}$ & Infusão & $\begin{array}{l}\text { Uso externo: } \\
\text { aplicar, } \\
\text { gelado, sobre } \\
\text { as pálpebras, } \\
\text { com auxílio de } \\
\text { algodão }\end{array}$ & $\begin{array}{l}\text { NEIVA; } \\
\text { NEIVA; } \\
\text { RIBEIRO } \\
(2013)\end{array}$ \\
\hline
\end{tabular}

Fonte: NEIVA; NEIVA; RIBEIRO (2013, p. 20). 
Quadro 2-Máscaras faciais caseiras desenvolvidas na oficina “Da planta ao fitocosmético"

\begin{tabular}{|l|l|l|}
\hline Máscara Facial & Componentes & Indicaçáa \\
\hline $\begin{array}{l}\text { Mamão } \\
\text { Revitalizante }\end{array}$ & $\begin{array}{l}1 \text { xícara de mamão e 1 colher } \\
\text { de sopa de mel }\end{array}$ & Pele seca - uso externo \\
\hline $\begin{array}{l}\text { Abacate } \\
\text { Hidratante }\end{array}$ & $\begin{array}{l}1 / 2 \text { abacate e } 1 \text { colher de sopa } \\
\text { de mel }\end{array}$ & Hidratante - uso externo \\
\hline $\begin{array}{l}\text { Aveia } \\
\text { Esfoliante }\end{array}$ & $\begin{array}{l}1 \text { colher de sopa de aveia, 1 } \\
\text { colher de sobremesa de mel e e } \\
1 / 2 \text { xícara de leite integral }\end{array}$ & $\begin{array}{l}\text { Esfoliaçáo da pele - uso } \\
\text { externo }\end{array}$ \\
\hline
\end{tabular}

Fonte: NEIVA; NEIVA; RIBEIRO (2013, p. 36).

As oficinas e os folhetos informativos despertaram o interesse dos alunos de todas as faixas etárias, porém, os alunos do ensino médio mostraram maior interesse principalmente sobre os fitocosméticos utilizados no tratamento e prevenção de acne.

O estabelecimento de uma comunicação clara e bastante integrativa pelos acadêmicos, ao disseminar conhecimentos na área de autocuidado, higiene, plantas medicinais e fitocosméticos no cotidiano da população, proporcionou uma conscientização da população frente a diversas situaçóes do uso de plantas e fitocosméticos no cotidiano. Provavelmente, a mudanças de hábitos e a consolidação de conhecimento desses alunos refletirá positivamente no grau educacional dos participantes e servirão de fonte de propagação desses conhecimentos para os seus familiares, pessoas próximas e sociedade.

O fácil acesso, o baixo custo e as tradiçôes familiares fazem com que as plantas se tornem alternativas atraentes representando, muitas vezes, a única alternativa à promoção da saúde de diversas populaçóes, principalmente as de baixa renda, em países subdesenvolvidos (SANTOS et al., 2016). A etapa de elaboração dos produtos de higiene e fitocosméticos, bem como a demonstração da sua utilização correta, foi significativa por permitir a autonomia dos estudantes no processo de autocuidado. Todas as práticas propostas foram planejadas com material de baixo custo de fácil acesso e adequadas às reais necessidades da sociedade. Isso contribuiu para o aumento do interesse e envolvimento dos alunos e professores. A oficina conseguiu estabelecer uma interaçáo dialógica, com troca de saberes, que contribuiu para a construção de uma sociedade mais justa, ética 
e democrática.

A interação com os professores das escolas públicas resultou na melhoria do ensino e no desenvolvimento do senso crítico dos alunos, e novas estratégias de consolidação do conhecimento e políticas de promoção da saúde e bem-estar. Os professores que participaram da oficina também são multiplicadores da informaçáo, e esses conhecimentos adquiridos servirão como facilitadores da inclusão de novas práticas didáticas, tornando as aulas mais dinâmicas, interativas, com novas abordagens do conhecimento, o que fortalecerá a qualidade do ensino.

Esse projeto de extensão também visou o contínuo aperfeiçoamento desses educadores, uma vez que eles participaram da construção das oficinas e do processo de elaboração de manuais e guias. Durante o projeto, houve a aproximação desses professores com a Universidade, despertando o interesse para qualificação e capacitação profissional.

A produção do conhecimento ocorreu por meio da troca do saber sistematizado, acadêmico e popular, tendo como consequência a democratização do saber, a participação da comunidade e uma produção resultando do confronto com a realidade. Enfatiza-se, ainda, a conexão entre cuidar, dialogar e produzir conhecimento, o que vem a promover a sensibilidade, o respeito e a capacidade perceptiva das necessidades alheias. As ações de ensino-pesquisa-extensão são alicerces fundamentais para o desenvolvimento institucional, pois todas oportunizam à comunidade acadêmica a ampliação e o aprimoramento dos seus conhecimentos, além de promover benefícios à sociedade (ROSÁRIO et al., 2013; NASCIMENTO; ROMERO, 2012).

\section{CONSIDERAÇÕES FINAIS}

O trabalho realizado foi de grande importância para todos os envolvidos. Aos alunos foi possibilitado o contato prévio com o mundo das ciências e a diminuição da distância entre o ensino fundamental e médio com a Universidade. Para os professores que acompanharam os alunos, o projeto possibilitou melhora no processo ensino-aprendizagem, possibilitando que os mesmos se sentissem 
incentivados a manter a criatividade em sala de aula. Isso é primordial para a manutenção da atenção dos alunos e para que o professor se sinta responsabilizado a ir à busca de transformar-se para melhor ensinar. Para os acadêmicos envolvidos, o projeto possibilitou o crescimento pessoal e, como futuros profissionais, a se responsabilizarem pela disseminação de conhecimento e informaçóes. Foram instigados, também, a criar aptidóes além do que lhes é ensinado em sala de aula.

Graças a todas as medidas objetivadas na criação e manutenção da oficina "Da planta ao fitocosméticos" houve uma conscientização visível de todos os alunos participantes, levando à mudança de hábitos e refletindo positivamente em seu desenvolvimento sociocultural.

\section{REFERÊNCIAS}

BENETTI, P. C.; SOUSA, A. I.; SOUZA, M. H. N. Creditação da extensão universitária nos cursos de graduação: relato de experiência. Revista Brasileira de Extensão Universitária, Santa Catarina, v. 6, n. 1, p. 25-32, 2015. Disponível em: <https://periodicos.uffs.edu.br/ index.php/RBEU/article/view/1951/pdf>. Acesso em: 2 dez. 2017.

BRANDEN, N. Como aumentar sua autoestima: aprenda a acreditar em si mesmo e a viver com confiança e otimismo. Rio de Janeiro: Sentante, 2009. p. 10-15.

BRASIL. Agência Nacional de Vigilância Sanitária. Formulário de Fitoterápicos da Farmacopeia Brasileira. Brasília: Anvisa, 2011. $126 \mathrm{p}$.

CORRÊA, P. M. et al. Vivências em promoção da saúde: articulando saberes com estudantes de escolas públicas. Extensio: Revista Eletrônica de Extensão, Florianópolis, v. 12, n. 19, p.14-24, 2015. Disponível em: <https://periodicos.ufsc.br/index.php/extensio/ article/view/18070221.2015v12n19p14/3046>. Acesso em: 30 nov. 2017.

DA SILVA, A. M. et al. O ensino de ciências biológicas: uma experiência teórico-prática com alunos do ensino médio de escolas públicas. Revista Brasileira de Extensão Universitária, Chapecó, 
v. 7, n. 2, p. 99-104, 2016. Disponível em: <https://periodicos.uffs. edu.br/index.php/\%20RBEU/article\%20/view/308>. Acesso em: 3 dez. 2017.

FIGUEIREDO, B. K. Desenvolvimento e estabilidade preliminar de um fitocosmético contendo extrato de chá verde (Camellia sinensis) (L.) Kuntze (Theaceae). Revista Brasileira de Farmácia, Rio de Janeiro, v. 95, n. 2, p. 770-788, 2014. Disponível em: <http:// www.rbfarma.org.br/files/637-25-11-2013-Desenvolvimento_e_ estabilidade_preliminar_de_um_fitocosmetico_contendo_extrato. pdf>. Acesso em: 10 abr. 2016.

FORPROEX - Fórum de Pró-Reitores de Extensão das Instituições Públicas de Educação Superior Brasileiras. Política Nacional de Extensáo Universitária. 2012. Disponível em: <http://www.ufmg.br/ proex/renex/documentos/2012-07-13-Politica-Nacional-de-Extensão. pdf >. Acesso em: 20 dez. 2017.

NASCIMENTO, T.; ROMERO, I. A indissociabilidade entre pesquisa e extensão nas universidades: o caso da ITES/UFBA. NAU Social, Salvador, v. 3, n. 5, p. 41-46, 2012.

NEIVA, P.; NEIVA, J.; RIBEIRO, C. Guia prático da beleza por dentro e por fora.. Rio de Janeiro Objetivo: 2013. p. 20-36.

OLIVEIRA, A. K. M. et al. Açóes educativas em saúde voltadas ao adolescente: um relato de experiência. Extensio: Revista Eletrônica de Extensão, Florianópolis, v. 13, n. 23, p.135-141, 2016. Disponível em: <https://periodicos.ufsc.br/index.php/extensio/article/ download/18070221.2016v13n23p135/32687>. Acesso em: 5 dez. 2017.

ROSÁRIO, C. L. et al. Indissociabilidade entre ensino, pesquisa e extensáo universitária: experiências nos cursos de licenciatura do Instituto Federal de Roraima. 2013. Disponível em: <https://www. aedb.br/seget/arquivos/artigos13/56218703.pdf >. Acesso em: 8 nov. 2017.

ROSSATO, A. E. et al. Fitoterapia racional: aspectos taxonômicos, agroecológicos, etnobotânicos e terapêuticos. Florianópolis: DIOESC, 2012. 211 p. Disponível em: <http://repositorio.unesc. net/bitstream/1/1628/2/Fitoterapia\%20Racional.pdf>. Acesso em: 
11 dez. 2017.

RUPPELT, B. M. et al. Plantas medicinais utilizadas na regiáo Oeste do Paraná. Curitiba: Editora da UFPR, 2015. 126 p.

SANTOS, J. A. A. et al. Diagnóstico e educação em saúde no uso de plantas medicinais: relato de experiência. Revista Ciências em Extensão, São Paulo, v. 12, n. 4, p. 183-196, 2016. Disponível em: <http://ojs.unesp.br/index.php/revista_proex/article/view/1408>. Acesso em: 17 out. 2017.

SANTOS, M. P. A extensão universitária como "laboratório" de ensino, pesquisa científica e aprendizagem profissional: um estudo de caso com estudantes do curso de licenciatura em pedagogia de uma faculdade particular do estado do Paraná. Extensio: Revista Eletrônica de Extensão, Florianopólis, v. 11, n. 18, p. 36-52, 2014. Disponível em: <https://periodicos.ufsc.br/index.php/extensio/ article/download/18070221.2014v11n18p33/28064>. Acesso em: 27 nov. 2017.

Submetido em 4 de janeiro de 2018.

Aprovado em 16 de abril de 2018. 